\title{
Stage I Vaginal Cancer AJCC v6 and v7
}

National Cancer Institute

\section{Source}

National Cancer Institute. Stage I Vaginal Cancer A/CC v6 and v7. NCI Thesaurus. Code C7856.

Stage I includes: (T1, N0, M0). T1: Tumor confined to vagina. N0: No regional lymph node metastasis. M0: No distant metastasis. (AJCC 6th and 7th eds.) 